\title{
The Engineering Characteristics and Classifications of Rock Masses along Road Section from Prambanan to Patuk, Yogyakarta, Indonesia
}

\author{
Aisyah Shahirah Juhari, I Gde Budi Indrawan, and Wahyu Wilopo \\ Department of Geological Engineering, Faculty of Engineering, Universitas Gadjah Mada, Yogyakarta, Indonesia
}

\begin{abstract}
Several attraction places and agricultural areas essential for tourism and villager to do their activities are located approximately $6 \mathrm{~km}$ along the road from Candi Ijo to Ngoro-Oro in between Prambanan and Patuk sub-districts Yogyakarta, Indonesia. The jointed rock masses along the road have the potential to fail. This paper describes rock masses' engineering characteristics and classifications along road sections from Prambanan to Patuk, Yogyakarta. The rock masses were characterized based on the Geological Strength Index (GSI) and Rock Mass Rating $(R M R)$ parameters. Laboratory tests were carried out to determine the intact rocks' Uniaxial Compressive Strength (UCS). The results show that the rock masses in the study area consisted of tuffaceous sandstone, fine tuff, coarse tuff, cemented tuffaceous sandstone, lapilli tuff, sandstone, laminated mudrock, and laminated tuffaceous sandstone. The rock masses had disintegrated, moderately disturbed, blocky, and very blocky structures and dominantly low weathering degrees. The intact rocks were classified as weak to very strong rocks. The discontinuities typically had medium to high persistence, close to wide spacing, very tight to wide apertures, and smooth to slightly rough surfaces. In addition, the discontinuities dominantly had no infillings, although discontinuities filled with less than $5 \mathrm{~mm}$ thick calcite were also commonly observed at several locations. The rock masses were completely dry during the field observation. Based on the $R M R$, the rock masses were classified as fair to good rocks. A new relationship between the GSI and RMR was suggested in this study.
\end{abstract}

Keywords: Engineering characteristics - Geological Strength Index (GSI) · Prambanan to Patuk · Rock Mass Rating $(R M R) \cdot$ Semilir Formation.

\section{INTRODUCTION}

The rock mass is an essential natural structure for rock mechanic engineering study when designing construction projects such as a dam, tunnel, and road cut (Hudson and Harrison, 1997). The stable rock mass structure will produce a high strength of the structure quality where the slopes geometry, groundwater, and geological condition act as the controlling factors of the stability.

Studying rock masses' geological condition and engineering properties is vital to prevent

\footnotetext{
*Corresponding author: I G. B. IndRAWAN, Department of Geological Engineering, Universitas Gadjah Mada. Jl. Grafika 2 Yogyakarta, Indonesia. E-mail: igbindrawan@ugm.ac.id
}

rock slope failure hazards leading to an accident, loss of properties, and high maintenance costs. According to Basahel and Mitri (2017), four methods can determine rock slope stability: kinematic, limit equilibrium, numerical, and empirical analyses. The rock mass classifications of Rock Mass Rating (RMR) (Bieniawski, 1989) and Geological Strength Index (GSI) (Marinos and Hoek, 2000; 2001) used in this study were the empirical methods. Both rock mass classifications were used to evaluate the quality of rock masses comprising the slopes.

According to Pantelidis (2009), several rock mass classification systems are used for tunneling and underground mining, namely $Q$ and 
RMR. According to Basahel and Mitri (2017), these rock mass classifications are only suitable for structurally controlled failures. For nonstructurally controlled failures, the Geological Strength Index (GSI) by Hoek et al. (1995) is more suitable. This classification is applied by visually examining rock masses exposed in outcrops, such as road cuts. According to Marinos and Hoek (2001), the quantification system is valid for rock masses classified in a range of 35 $<$ GSI $<75$.

Several tourist attractions and agricultural areas essential for tourism and villager to do their activities are located approximately $6 \mathrm{~km}$ along Candi Ijo to Ngoro-Oro in between Prambanan and Patuk sub-districts (Figure 1). Many jointed rock masses have the potential to fail beside the road. The study area is located in the Southern Mountains of Central Java. The Southern Mountains are occupied by structural hills consisting of several rock formations, such as Semilir, Nglanggran, and Kebobutak Formations. The rock formations comprise steep to very steep slopes. According to Surono et al. (1992), there are two regional faults: strike-slip and normal fault close to the study area. The study area and the surroundings have a high to very high susceptibility to a landslide (e.g., Santosa, 2005; Priangga et al., 2018).

This paper presents the engineering characteristics of the rock masses of the Semilir Formation along the road of Prambanan and Patuk sub-districts. The results presented in this paper were essentially the preliminary results of a study to evaluate the stability of the rock slopes along the road of Candi Ijo to Ngoro-Oro.

\section{METHOD}

Fieldworks and laboratory tests investigated the engineering characteristics of the rock masses in the study area. Five outcrop stations were selected in the Semilir Formation, namely STA1, STA2, STA3, STA4, and STA5, as shown in Figure 1. The outcrops were selected due to the high susceptibility to landslide, steep to a very steep slope, and similarity in the lithological units. Each outcrop was divided into sections having similar rock types and different intensities of geological structure. The window mapping length for each section was $4 \mathrm{~m}$. The rock type was identified based on the classifications proposed by Pettijohn (1975) and Schmid (1981). The rock mass classifications were based on the GSI and RMR systems. The general GSI chart for common rock mass suggested by Marinos and Hoek (2000) and the modified GSI chart for heterogeneous rock masses developed by Marinos and Hoek (2001) was used to determine the rock mass quality on the GSI. The parameters considered in the GSI are rock mass structure and condition of discontinuity surface. The parameters used in RMR classification were Unconfined Compressive Strength (UCS) of intact rock, Rock Quality Designation $(R Q D)$, the spacing between discontinuities, conditions of discontinuities, and groundwater condition. The UCS values were obtained by converting the point load index values following the Equation 1 expressed as (Bieniawski, 1975).

$$
U C S=24 I s_{(50)}
$$

where $I s_{(50)}=$ point load index of rock sample having $50 \mathrm{~mm}$ diameter.

The $R Q D$ was taken in the field by using the suggested Equation 2 proposed by Priest and Hudson (1976).

$$
R Q D=100 e^{-0.1 \lambda}(1+0.1 \lambda)
$$

where:

$$
\lambda=\frac{\text { number of discontinuities }}{\text { length }(m)}
$$

where $\lambda$ is known as the total joint frequency. The total joint frequency formula can be calculated by discontinuities total number intercepting at length $(L)$ in any interest direction. In $R M R$ calculation, the summation rating of parameters is shown in the Equation 4.

$$
R M R=R_{1}+R_{2}+R_{3}+R_{4}+R_{5}
$$

where $R_{1}=U C S ; R_{2}=R Q D ; R_{3}=$ discontinuity spacing; $R_{4}=$ discontinuity conditions (persistence, aperture, roughness, infilling, and weathering); and $R_{5}=$ groundwater condition. The field descriptions of intact rock strength, spacing and discontinuities, and groundwater conditions followed the ISRM (1978). Hoek et al. (1995) proposed an equation to determine the 


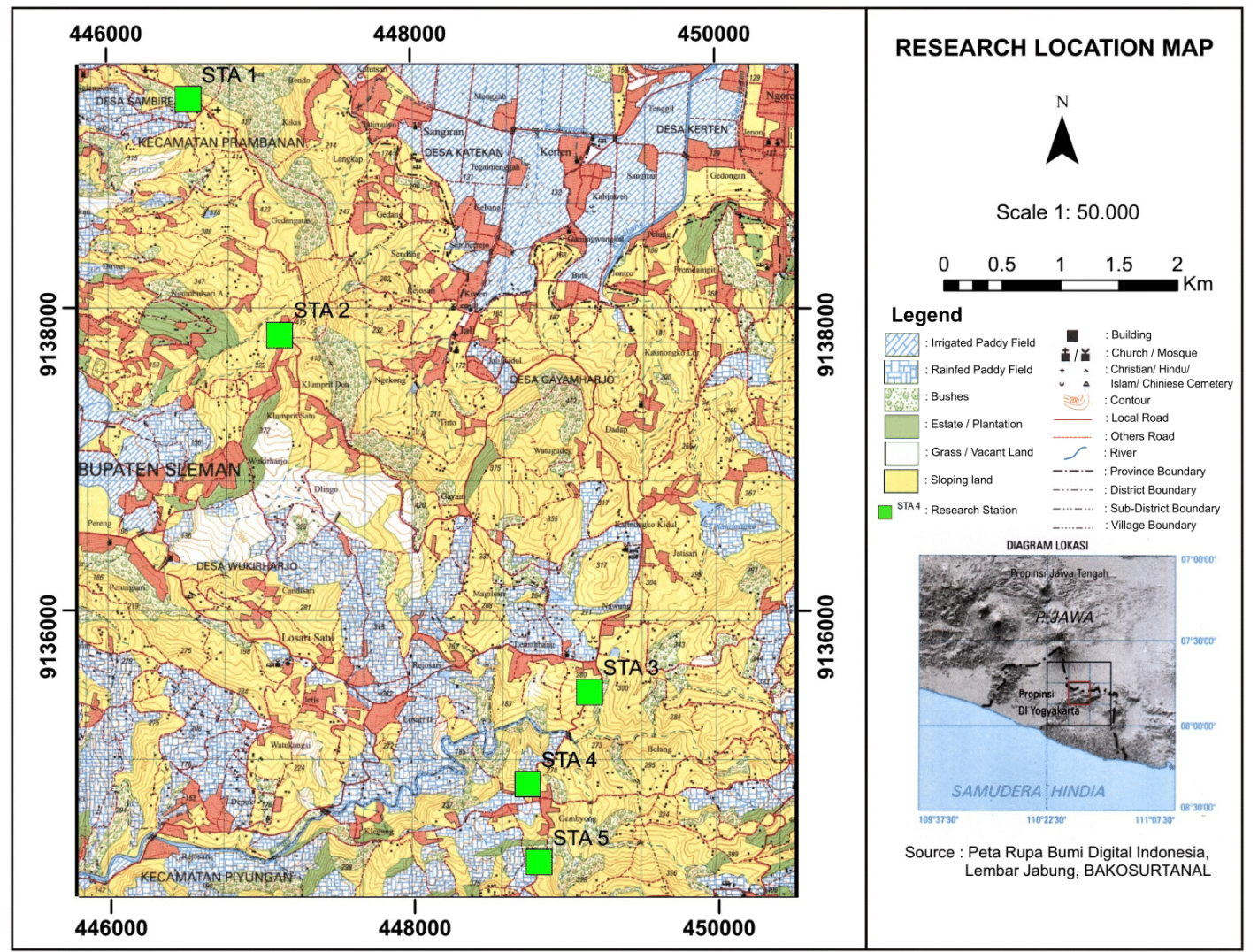

FIGURE 1. Location of the study area.

relationship between $G S I$ and $R M R$ for $R M R$ $>23$ as follows:

$$
G S I=R M R_{89}-5
$$

where $R M R_{89}$ is a basic rock mass rating with the groundwater rating $=15$ (dry) and the adjustment for joint orientation $=0$ (very favorable).

\section{RESUlts AND Discussion}

Figure 3 shows the rock masses at the STA1 that consisted of tuffaceous sandstone and fine tuff. The UCS values of the intact rocks of the tuffaceous sandstone and fine tuff were 20 and $15 \mathrm{MPa}$, respectively, which were classified as weak intact rocks. Slightly weathered rock masses dominated this station. However, section D consisted of moderately weathered rock masses (Figure 2). The rock masses had $R Q D$ values ranging from 51 to $95 \%$ and mostly blocky to very blocky rock mass structures. The discontinuities had typically less than $10 \mathrm{~m}$ persistence (medium persistence), $60-600 \mathrm{~mm}$ spacing (close to moderate spacing), less than $1 \mathrm{~cm}$ aperture width (very tight to wide aper- ture), slightly rough surface, and several types of infillings, such as sand and oxide materials. The rock masses were completely dry during the field observation. Figure 8 shows the quality of the rock masses at the STA1. Based on the $R M R$, the rock masses at this station were classified into fair to good rock.

Figure 4 shows the lithologies at the STA2, which consisted of coarse tuff and fine (vitric) tuff. The rock masses were divided into two zones (Figure 2). Both zones dominantly contained slightly weathered rock masses. However, the rock masses in Zone 2 were partly altered into moderately weathered. The average $U C S$ values of the intact rocks of the coarse tuff and vitric tuff were 23 and $16 \mathrm{MPa}$, respectively. Both lithologies were classified as weak intact rocks based on the UCS values. The coarse tuff rock masses had 91 to $99 \%$ $R Q D$ values and a blocky structure. The discontinuities had 1-10 m for persistence (low to medium persistence), $60-2000 \mathrm{~mm}$ spacing (close to wide spacing), less than $10 \mathrm{~cm}$ aperture width (very tight to moderately wide aperture), slightly rough surface, and mostly no in- 


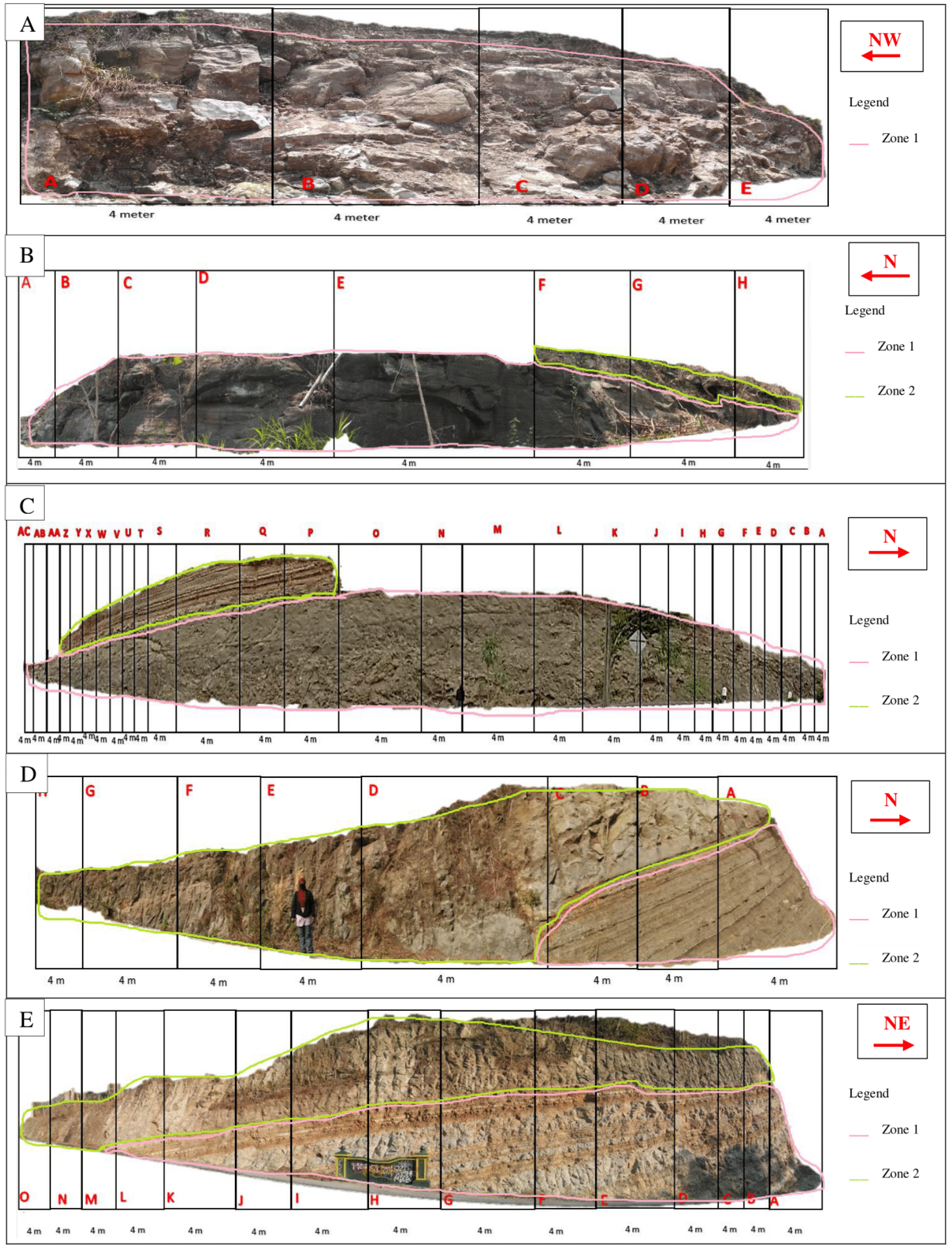

FIGURE 2. Photographs of rock masses in the study area: a) STA1; b) STA2; c) STA3; d) STA4; and e) STA5. 


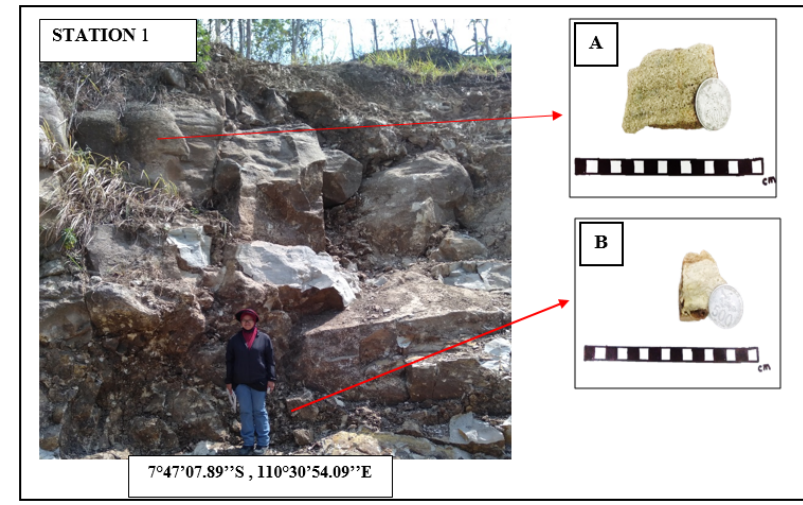

FIGURE 3. Rock masses at STA1: a) Tuffaceous sandstone b) Fine tuff.

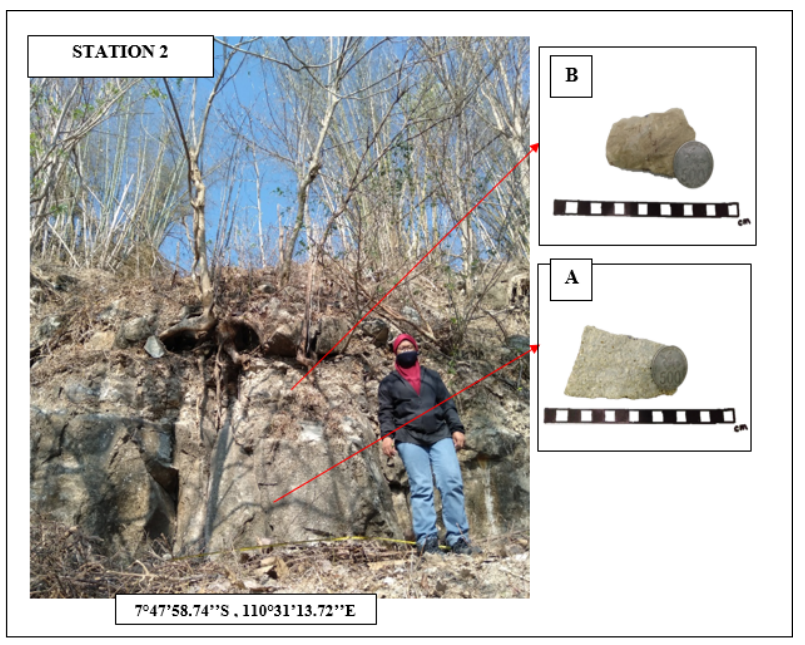

FIGURE 4. Rock masses at STA2: a) coarse tuff b) fine tuff.

fillings. Meanwhile, the vitric tuff rock masses had 78 to $91 \% R Q D$ values and a very blocky structure. The discontinuities had 1 to $10 \mathrm{~m}$ for persistence (low to medium persistence), 60-200 mm spacing (close spacing), 0.25-20 cm aperture width (wide to extremely wide aperture), smooth and rough surfaces, and no infillings. The rock masses were completely dry during the field mapping. Based on the RMR, the rock masses at the STA2 were dominantly categorized into good rock (Figure 8).

The rock masses at the STA3 consisted of tuffaceous sandstone, lapilli tuff, cemented tuffaceous sandstone, and layered tuffaceous sandstone (Figure 5). The rock masses were divided into two zones (Figure 2). Zone 1 dominantly contained unweathered rock masses and slightly weathered rock masses. On the other hand, Zone 2 consisted of moderately weath- ered rock masses. The average UCS values of the intact rocks of the tuffaceous sandstone, lapilli tuff, and cemented tuffaceous sandstone were 42,37 , and $160 \mathrm{MPa}$, respectively. Based on the UCS values, the tuffaceous sandstone and lapilli tuff were classified as moderately strong rocks, while the cemented tuffaceous sandstone was classified as very strong rock. Zone 1 had a blocky to very blocky rock mass structure, while Zone 2 had a moderately disturbed rock mass structure. Zone 1 and 2 had $R Q D$ values of $71-99 \%$ and $92-100 \%$, respectively. The discontinuity in both zones had a 1 to $10 \mathrm{~m}$ persistence (low to medium persistence). The discontinuity spacing in Zone 1 ranged from 60 to $2000 \mathrm{~mm}$ (close to wide spacing) for different discontinuities sets, while that in Zone 2 ranged from 20 to $600 \mathrm{~mm}$ (very close to moderate spacing). The aperture width of discontinuity varied from 0.01 to $1 \mathrm{~cm}$ (wide aperture) in the tuffaceous sandstone, lapilli tuff, and cemented tuffaceous sandstone. The surface roughness for tuffaceous sandstone was very rough to smooth, cemented tuffaceous sandstone was smooth to slickenside, and lapilli tuff was slightly rough and smooth. In general, the discontinuities had no infilling materials. However, more than $1 \mathrm{~mm}$ thick infilling materials, such as calcite, were observed in the lapilli tuff. Based on the standard field indices, the discontinuities wall strength was classified as firm for the tuffaceous sandstone, medium-strong for the lapilli tuff, and very strong for the cemented tuffaceous sandstone. The rock masses at the STA3 were completely dry during the field mapping. Figure 8 shows that the rock masses at this station were dominated by good rock.

Figure 6 shows the rock masses at the STA4. The rock masses were divided into two zones (Figure 2). Zone 1 consisted of sandstone and laminated mudrock, while Zone 2 consisted of lapilli tuff. The rock masses in both zones were slightly weathered. The average UCS values of the intact rocks of the sandstone, laminated mudrock, and lapilli tuff were 30,51 , and $8 \mathrm{MPa}$, respectively. Based on the UCS values, the sandstone was classified as moderately strong rock, the laminated mudrock was classified as strong rock, and the lapilli tuff was classified 


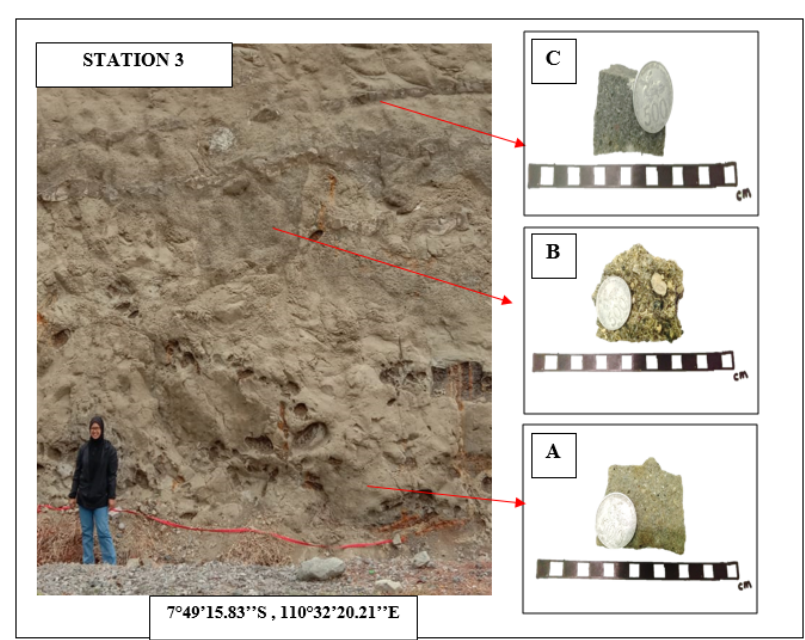

FIGURE 5. Rock masses at STA 3: a) tuffaceous sandstone; b) lapilli tuff; c) cemented tuffaceous sandstone.

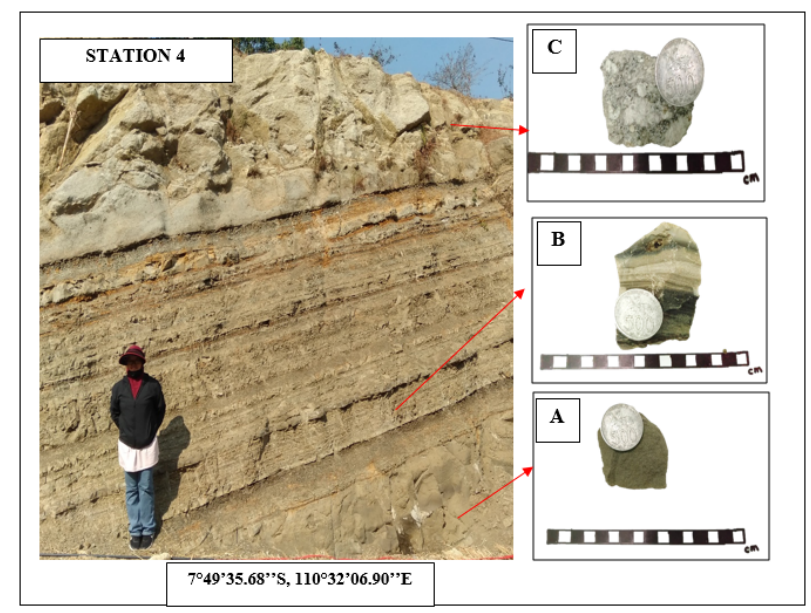

FIGURE 6. Rock masses at STA4: a) Sandstone; b) Laminated mudrock; c) Lapilli tuff.

as weak rock. Zone 1 consisted of a rock mass structure of blocky to very blocky lapilli tuff.

Meanwhile, Zone 2 consisted of rock mass structures of moderately disturbed sandstone interlayers with laminated mudrock, moderately disturbed laminated mudrock interlayers with sandstone sparse, and disintegrated fault zone. The $R Q D$ values of the rock mass in Zone 1 and Zone 2 were 37-78 \% and 78-98 \%, respectively. The discontinuity persistence in Zone 1 was in the range of fewer than $3 \mathrm{~m}$ to 10-20 m (medium to high persistence), while that in Zone 2 was less than $10 \mathrm{~m}$ (very low to medium persistence). The discontinuity spacings in Zone 1 and Zone 2 were in the range of 60 to $2000 \mathrm{~mm}$ (close to wide spacing) and
20 to $2000 \mathrm{~mm}$ (very close to wide spacing), respectively. The aperture width of discontinuity in each of the lithologies varied, where the sandstone, laminated mudrock, and lapilli tuff had $0.25-0.5 \mathrm{~mm}$ (partly open aperture), less than $0.1 \mathrm{~mm}$ (very tight aperture), and less than $2.5 \mathrm{~mm}$ (very tight to open aperture) aperture widths, respectively. The discontinuity surfaces of the lapilli tuff were slightly rough, while those of the laminated mudrock and sandstone had smooth and slickenside. The infilling materials of the discontinuities were typically less than $1 \mathrm{~mm}$ thick calcite. Based on the strength measurements using the standard field indices, the discontinuity walls in the lapilli tuff were classified as weak, while those in the sandstone and laminated mudrock were classified as moderate to strong. During the field investigation, the groundwater condition of the rock masses in this station was dry. Based on the RMR, the rock masses at the STA4 were categorized into fair to good rock (Figure 8).

The rock mass zones in the STA 5 are shown in Figure 2, while lithologies comprising this station are shown in Figure 7. Zone 1 consisted of fine (vitric) tuff, laminated tuffaceous sandstone, and sandstone, while Zone 2 consisted of coarse tuff. The rock masses were slightly weathered. The average UCS values of the intact rocks of the fine tuff, laminated tuffaceous sandstone, sandstone, and coarse tuff were 18, 18,21 , and $13 \mathrm{MPa}$, respectively. All intact rocks in this station were classified as weak rocks based on the UCS values. Zone 1 contained two types of rock mass structures: moderately disturbed and disintegrated rock mass structures. The latter comprised the fault zone. Meanwhile, the coarse tuff in Zone 2 had a blocky to very blocky rock mass structure. The average $R Q D$ values of the rock mass in Zone 1 and Zone 2 were 31-92 \% and 81-99 \%, respectively. The discontinuity persistence in Zone 1 was less than $20 \mathrm{~m}$ (very low to high persistence), while in Zone 2 was less than $10 \mathrm{~m}$ (very low to medium persistence). The discontinuity spacings in Zone 1 and Zone 2 were in the range of $20-600 \mathrm{~mm}$ (very close to moderate spacing) and 20-2000 mm (very close to wide spacing), respectively. The aperture width of discontinuity in Zone 1 was $0.1-2.5 \mathrm{~mm}$ (tight to open aperture), while Zone 2 was domi- 


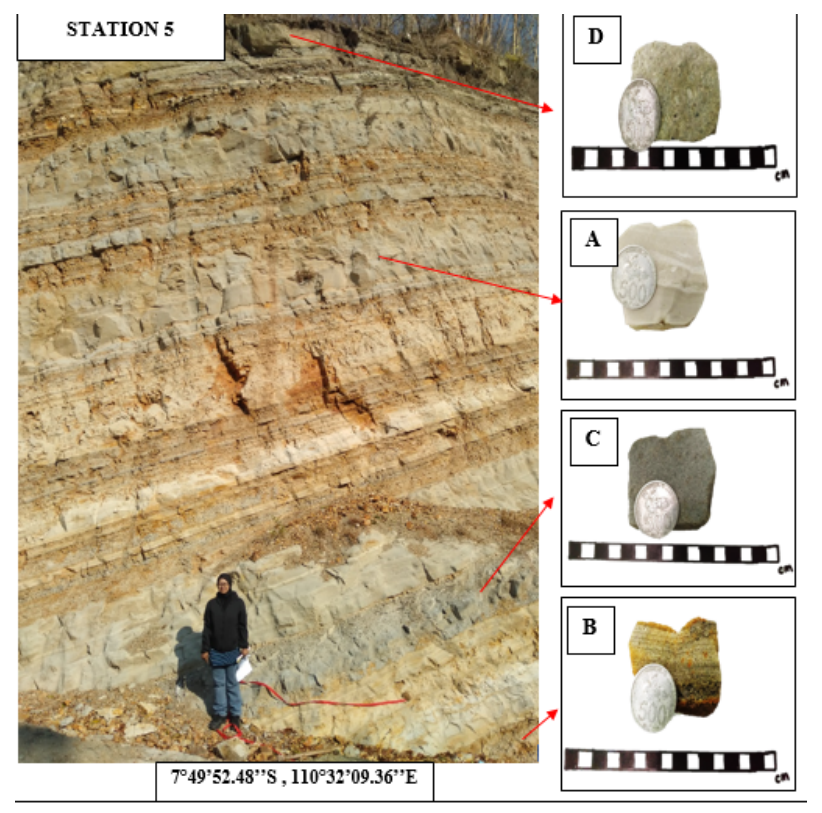

FIGURE 7. Rock masses at STA5: a) fine tuff; b) laminated tuffaceous sandstone; c) sandstone d) coarse tuff.

nantly less $0.25 \mathrm{~mm}$ (very tight to tight aperture). Slightly rough discontinuity surfaces were dominantly observed in both zones, although several smooth and slickenside discontinuity surfaces were also observed. The discontinuities in Zone 1 were dominantly filled with 1-5 mm thick calcite and oxide materials, while those in Zone 2 were unfilled. The discontinuity walls typically had a low strength based on the standard field indices. During the field investigation, no sign of groundwater was observed in the rock masses at this station. As shown in Figure 8, the rock masses at the STA5 were classified into fair to good rock.

Figure 9 shows the GSI values of the rock masses at all stations plotted against the RMR values. The relationship between GSI and $R M R$, described in Equation 5, is also shown for comparison. It is shown that the linear equation resulting from this study was nearly close to the equation proposed by Hoek et al. (1995). The relationship between the GSI and RMR obtained in this study can be represented by a linear equation (Equation 6).

$$
G S I=0.7 R M R_{b}+13
$$

The relationship allows estimating the quality of similar rock masses, particularly rock masses of the Semilir Formation, based on the
GSI data or estimating the rock masses' strength based on the available $R M R$ data.

\section{CONCLUSION}

Fieldworks and laboratory tests were conducted to characterize the rock masses' engineering properties along the road from Candi Ijo to Ngoro-Oro between Prambanan and Patuk sub-districts in Yogyakarta, Indonesia. The results show that the rock masses in the study area consisted of tuffaceous sandstone, fine tuff, coarse tuff, cemented tuffaceous sandstone, lapilli tuff, sandstone, laminated mudrock, and laminated tuffaceous sandstone. The rock masses had disintegrated, moderately disturbed, blocky, and very blocky structures and dominantly low weathering degrees. The intact rocks were classified as weak to very strong rocks. The discontinuities typically had medium to high persistence, close to wide spacing, very tight to wide apertures, and smooth to slightly rough surfaces. In addition, the discontinuities dominantly had no infillings, although discontinuities filled with less than $5 \mathrm{~mm}$ thick calcite were also commonly observed at several locations. The rock masses were completely dry during the field observation. Based on the $R M R$, the rock masses were classified as fair to good rocks. The relationship between GSI and $R M R$ obtained in this study was in reasonably good agreement proposed by Hoek et al. (1995).

\section{ACKNOWLEDGEMENTS}

The first author would like to thank Gadjah Mada International Fellowship (GMIF) for sponsoring the scholarship. The assistance of Ms. Afrilita and Mr. Muhammad Virgiawan Agustin in conducting fieldwork and laboratory tests is gratefully acknowledged.

\section{REFERENCES}

Basahel, H. and Mitri, H. (2017) Journal of Rock Mechanics and Geotechnical Engineering Application of Rock Mass Classification Systems to Rock Slope Stability Assessment: A Case Study, Journal of Rock Mechanics and Geotechnical Engineering. Vol.9, no.6, p. 993-1009.

Bieniawski, Z. T. (1975) The point-load test in geotechnical practice. Engineering Geology. Elsevier, The Netherlands, 9, pp 1-11.

Bieniawski, Z. T. (1989) Engineering Rock Mass Classifications: A Complete Manual for En- 
JUHARI et al.

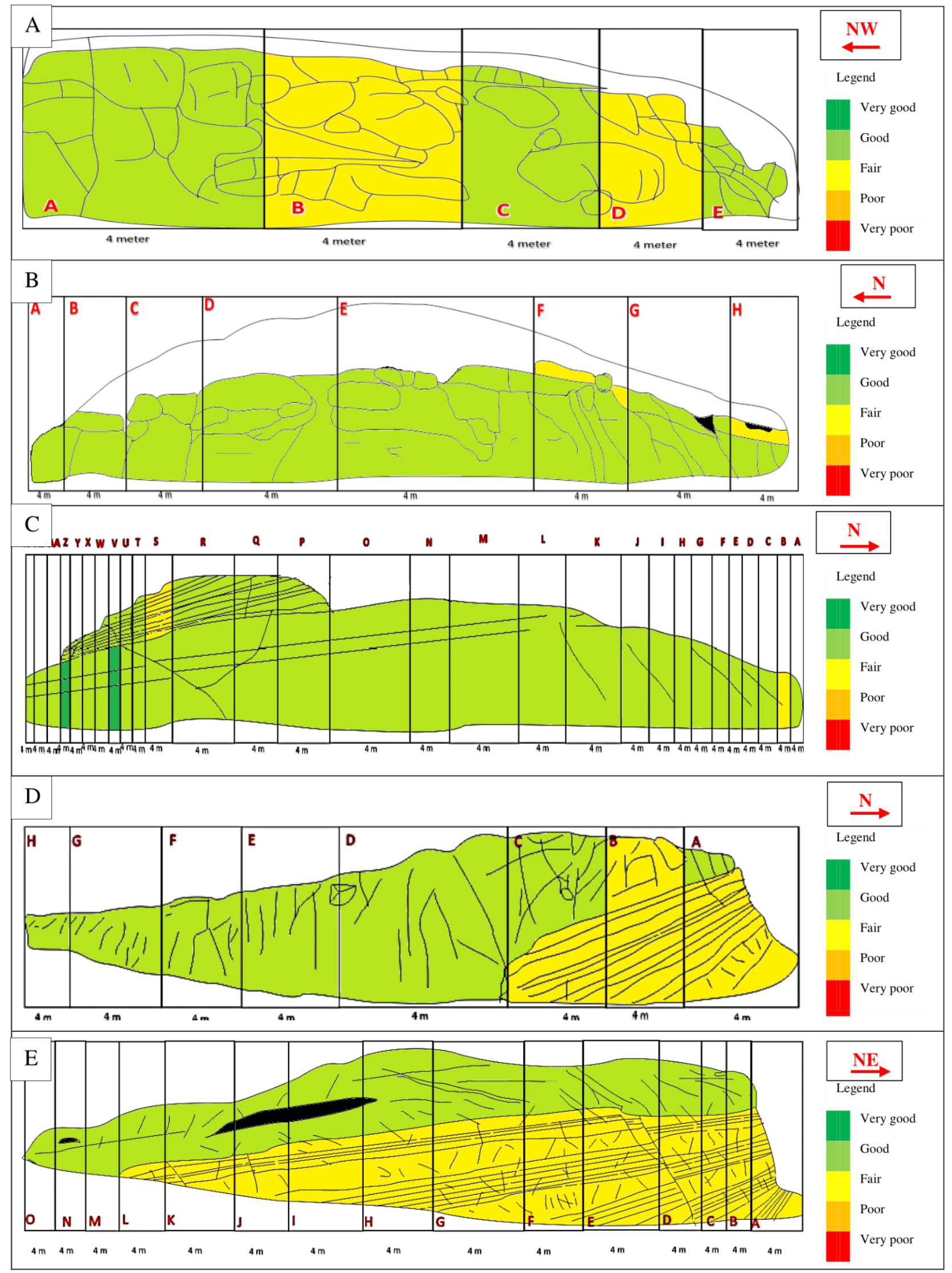

FIGURE 8. Rock mass qualities determined by the RMR: a) STA1; b) STA2; c) STA3; d) STA4; and e) STA5. 


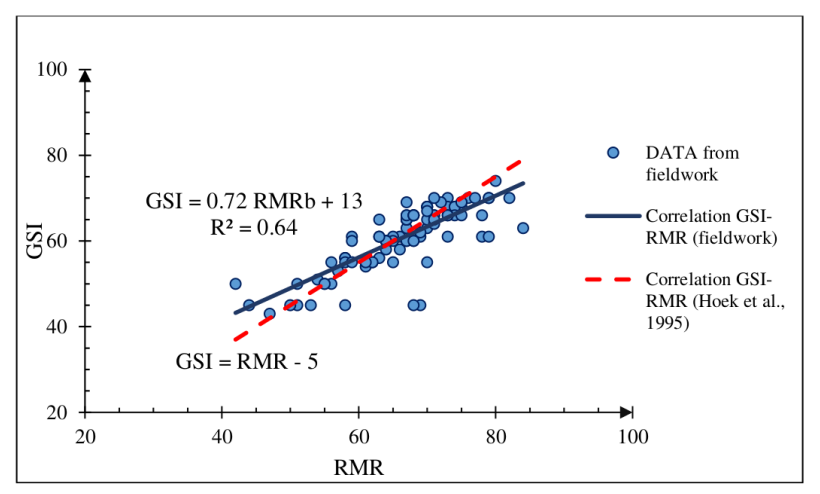

FIGURE 9. Relationship between GSI and RMR.

gineers and Geologists in Mining, Civil and Petroleum Engineering. New York: Wiley.

Hoek, E., Kaiser, P. K. and Bawden W.F. (1995) Support of Underground Excavations in Hard Rock. Rotterdam: Balkema. Hudson, J. A and Harrison, J. P. (1997) Engineering Rock Mechanics: An Introduction to the Principles.

ISRM. (1978) Suggested methods for the quantitative description of discontinuities in rock masses. International Journal of Rock Mechanics and Mining Sciences \& Geomechanics Abstracts. Vol. 15, p.319-368.

Marinos, P. and Hoek, E. (2000) GSI-A Geologically Friendly Tool for Rock Mass Strength Estimation, In Proc. Geoeng2000 Conference. Melbourne.

Marinos, P. and Hoek, E. (2001) Estimating The
Geotechnical Properties of Heterogeneous Rock Masses such as Flysch, Bulletin of Engineering Geology and The Environment, vol.60, no.2, p. 85-92.

Pettijohn, F. J. (1975) Sedimentary Rocks. 3rd Edn. New York: Harper \& Row Publishers.

Priangga, E., Pramumidjojo, S. and Satyarno, I. (2018) The Risk of Slope Stability Due To Earthquake (Case Area In Patuk District, Gunung Kidul Regency), Semesta Teknika, vol.21, p. 93105.

Priest, S. D., and Hudson, J. A. (1976) Discontinuity Spacings in Rock, International Journal of Rock Mechanics and Mining Sciences \& Geomechanics Abstracts, vol 13, No.5, p. 135-148.

Santosa, L. W. (2005) Identification of Land Degradation and Method of Solution in Zone of Baturagung Hill at Gunung Kidul Regency, Forum Geografi, vol.19, p.30-54.

Schmid, R. (1981) Descriptive Nomenclature and Classification of Pyroclastic Deposits and Fragments - Recommendations of the IUGS Subcommission on the Systematics of Igneous Rocks, Geologische Rundschau, vol.70, no.2, p. 794-799.

Surono, Toha, B., and Sudarno, I. (1992) Geological Map of the Surakarta Giritontro Quadrangles, Jawa, Lembar (Quadrangle) 1408-3 \& 14076, Skala (Scale) 1:100.000. Pusat Penelitian dan Pengembangan Geologi. Departemen Pertambangan dan Energi. 